\title{
Zelfwaardering, zelfbepaling en authenticiteit: visies vanuit de sociale psychologie
}

\author{
Roos Vonk
}

\section{Inleiding}

Mensen hebben een fundamentele, diep verankerde behoefte aan een positief zelfbeeld. Over de oorzaken daarvan wordt onder psychologen flink gedebatteerd (Leary \& Baumeister, 2000; Greenberg, Solomon \& Pyszczynski, 1997). In dit artikel richt ik me op de sociale gevolgen van de behoefte aan zelfwaardering; op de vraag wat de optimale manier is om zelfwaardering te bereiken; en op de vraag of verschillende vormen van zelfwaardering verschillende consequenties hebben voor het functioneren in werk en sociale relaties. Het zijn vragen waarop door de sociale psychologie in de loop der tijd verschillende en deels tegenstrijdige antwoorden zijn gegeven. In de slotparagraaf wordt toegewerkt naar een synthese daarvan.

\section{Het totalitaire ego}

Vaak wordt aangenomen dat zelfwaardering de sleutel is naar een gelukkiger leven en zelfs een betere samenleving. Lage zelfwaardering is geassocieerd met lage mentale en lichamelijke gezondheid (Taylor \& Brown, 1988, Taylor< Lerner, Sherman, Sage \& McDowell, 2003), instabiliteit in relaties (Murray ,Holmes, Griffin, Bellavia \& Rose, 2001), depressie (Alloy \& Abramson, 1979), sociale angst (Leary \& Kowalski, 1995), en een slecht vermogen om met stress en tegenslag om te gaan (Steele, 1988). Op die manier bekeken zou zelfwaardering de oplossing voor vele problemen kunnen zijn. Gelukkig hébben de meeste mensen een hoge zelfwaardering: Bij zelfrapportage (bijvoorbeeld de uitspraak "Al met al ben ik tevreden met mezelf") scoort de overgrote meerderheid aan de positieve kant van de antwoordschaal (in ons onderzoek: 87 tot 90 \%; Vonk, Jolij, Stoeller \& Boog, 2004). Sterker nog, de meeste mensen hebben een onrealistisch positief zelfbeeld. Bijvoorbeeld: onder Amerikaanse high school-leerlingen, rekent $25 \%$ zichzelf als behorend tot de beste $1 \%$ wat betreft sociale vaardigheden (Gilovich, 1991); 90\% van de autorijders vindt zichzelf een betere bestuurder dan gemiddeld (Svenson, 1981); en 94\% van de universitair docenten ziet zichzelf als beter in hun baan dan de gemiddelde collega (Cross, 1977).

We zien hier al dat er ook een keerzijde is aan hoge zelfwaardering: het hangt samen met allerlei vormen van zelfbedrog. Om er slechts enkele te noemen (voor overzichten, zie o.a. Baumeister, 1998; Blaine \& Crocker, 1993; Crocker \& Park, 2003; Koole, 2004), mensen met een hoge zelfwaardering:

- schrijven hun mislukkingen en morele fouten toe aan externe factoren, en hun successen en verdiensten aan interne factoren (zelf-dienende vertekening);

- vergelijken zichzelf met anderen die slechter af zijn (neerwaartse sociale vergelijking);

- stereotyperen en devalueren leden van andere groepen ('outgroup derogation')

- onthouden hun successen beter dan hun mislukkingen (selectieve herinnering);

- besteden meer aandacht aan positieve dan aan negatieve informatie over zichzelf;

- zien hun goede eigenschappen als uniek en bijzonder, en hun slechte eigenschappen als heel normaal; 
bagatelliseren het belang van kwaliteiten waar ze niet hoog op scoren; doen negatieve feedback af als onbetrouwbaar of vertekend; overschatten hun eigen aandeel in groepsbeslissingen en -activiteiten; slaan zich op de borst vanwege de successen van andere personen met wie ze zijdelings geassocieerd zijn ('basking in reflected glory');

vinden iemand die tegen hen slijmt aardiger en geloofwaardiger dan een neutrale buitenstaander die het slijmgedrag waarneemt.

In het algemeen kunnen we zeggen dat de werkelijkheid wordt verstoord om de zelfwaardering te beschermen. Er is dan ook geen enkel verband tussen de vleiende beelden die mensen van zichzelf hebben en meer objectieve maten (Ehrlinger \& Dunning, 2003). Bijvoorbeeld: hoewel er een hoge correlatie is tussen zelfwaardering en het eigen oordeel over hoe aantrekkelijk men is ( $\mathrm{r}=.85$; Harter, 1993), ligt de correlatie van dit oordeel met beoordelingen van objectieve buitenstaanders heel dicht bij 0 (Diener, Wolsic \& Fujita, 1995). Op analoge wijze is zelfwaardering gecorreleerd met het eigen oordeel over de intelligentie $(\mathrm{r}=.35)$, maar niet met IQ scores ( $\mathrm{r}=-.07$; Gabriel, Critelli \& Ee, 1994).

In veel opzichten kan het ego van mensen met een hoge zelfwaardering worden vergeleken met een totalitair regime (Greenwald, 1980) waarin informatie wordt gemanipuleerd en verdraaid om het gewenste beeld tot stand te brengen. Ook Wilson (2002) heeft het zelf beschreven als een zeer creatieve en actieve 'spin doctor'.

Hoewel sommige verstoringen heel functioneel kunnen zijn (Taylor c.s., 1988, 2003), hebben ze ook negatieve consequenties. Allereerst zijn die consequenties onaangenaam voor andere mensen (Baumeister e.a., 2003). Hoewel mensen met hoge zelfwaardering in het algemeen evenwichtig en goed aangepast zijn, kan hun gedrag sterk veranderen wanneer hun ego wordt bedreigd; wanneer ze worden geconfronteerd met afwijzing of kritiek, hebben ze de neiging om:

- zich agressief en vijandig op te stellen tegenover de ander en het die persoon betaald te willen zetten (Baumeister, Smart \& Boden, 1996; Jansen \& Vonk, 2004);

- zichzelf te willen rehabiliteren door bijvoorbeeld sterk op te scheppen over hun kwaliteiten (cf. Heatherton \& Vohs, 2000; Vohs \& Heatherton, 2001);

- anderen omlaag te halen (bijv. Aberson, Healy \& Romero, 2000);

- vast te houden aan hun eigen zelf-dienende interpretaties, waardoor in potentie conflicten kunnen ontstaan met de (mogelijkerwijs eveneens zelf-dienende) interpretaties van vrienden, partners of collega's (Gilovich, Kruger \& Savitsky, 1999; Leary, 2002).

Wellicht als gevolg van dit alles worden mensen met hoge zelfwaardering niet erg aardig gevonden wanneer hun ego net bedreigd is (Heatherton \& Vohs, 2000; Joiner, Vohs, Katz, Kwon \& Kline, 2003; cf. Vonk, 2001). Ze reageren dan defensief en zijn opvallend ongeïnteresseerd in informatie die hen daadwerkelijk zou kunnen helpen hun tekortkomingen te herstellen (cf. Baumeister \& Tice, 1985).

Zelfwaardering is dus kennelijk niet de panacee waar velen op hebben gehoopt (cf. Dawes, 1994; Damon, 1995; Hewitt, 1998; London, 1997). Alleen door middel van een rigide, defensief regime kunnen mensen hun zelfwaardering handhaven, en daarmee een groot deel van hun levensvreugde (Vonk, 2002). Dit betekent dat ze niet in staat zijn de dingen te zien 
zoals ze werkelijk zijn (Baumeister, Heatherton \& Tice, 1993; Sedikides, 1993) en dat ze geen realistische kijk hebben op hoe anderen hen zien (Shrauger \& Schoeneman, 1979). De belangen die op het spel staan verhinderen hen op onpartijdige wijze naar de feiten te kijken. Dit zou wel eens met name kunnen gelden voor mensen in hoge functies; door de verkregen macht en status gaat hun zelfwaardering omhoog (Kipnis, 1976), terwijl het tegelijkertijd voor ondergeschikten steeds moeilijker wordt om kritiek te geven en de waarheid te zeggen; hoe machtiger men is, hoe meer anderen geneigd zijn om te slijmen, wat het onrealistische zelfbeeld verder versterkt (vgl. Jones, 1964; Vonk, 1998).

Helaas zijn mensen met een lagere zelfwaardering weliswaar realistischer, maar ook vaker ongelukkig, depressief en niet erg geneigd om dingen aan te pakken. Er is dus kennelijk sprake van een 'trade-off' tussen een goed gevoel over jezelf hebben en realistisch en accuraat zijn (Colvin \& Block, 1994; Lyubomirsky, 2001, Taylor, 1989). Hoewel de meeste lezers waarschijnlijk vinden dat ze in dit dilemma moeten kiezen voor de realiteit, en dat ze dat ook doen, is het belangrijk te beseffen dat dit in de meeste gevallen een onjuiste conclusie is: ook in dit opzicht bestaat er illusoire superioriteit. De meeste mensen denken ten onrechte dat hun percepties meer accuraat en minder geflatteerd zijn dan die van anderen (Armor, 1999; Pronin, Lin \& Ross, 2002).

\section{De voordelen van 'echte' zelfwaardering: authenticiteit, motivatie en inspiratie}

Een mogelijke uitweg uit het spanningsveld tussen zelfwaardering en realisme wordt geboden door de self-determination theorie (bijv. Deci \& Ryan, 1995, 2002). Volgens deze theorie komt 'echte' zelfwaardering van binnenuit; deze ontstaat vanzelf bij een hoge selfdetermination (zelfbepaling), dat wil zeggen, wanneer je (a) in contact staat met wie je echt bent en wat je wilt, en (b) de vrijheid ervaart om autonome keuzes te maken die passen bij wie je bent. Dit uitgangspunt heeft geleid tot het onderscheid tussen 'echte' en defensieve zelfwaardering (Kernis, 2003). . Echte zelfwaardering is stabiel (d.w.z. is over de tijd heen niet aan sterke schommelingen onderhevig) en is niet afhankelijk van de vraag of men wel aardig gevonden wordt, succesvol is, er leuk uitziet etc. Defensieve zelfwaardering daarentegen is kwetsbaar: men heeft voortdurend bevestiging nodig om de zelfwaardering in stand te houden.

De hiervoor beschreven onderzoeksresultaten over de negatieve gevolgen van zelfwaardering gaan, volgens de self-determination theorie, eerder over de defensieve vorm van zelfwaardering. Deze is afhankelijk van externe bevestiging, bijvoorbeeld waardering van anderen, goede prestaties, succes, status of macht. Dit impliceert dat datgene wat veel mensen voortdurend doen - hun zelfwaardering zoeken via anderen - in feite een averechts effect heeft. Je past je aan aan wat anderen van je willen en verwachten; hierdoor verlies je het contact met je innerlijke drijfveren, dat volgens de self-determination theorie juist zo essentieel is om 'echte' zelfwaardering te bereiken. Als gevolg hiervan moet je weer de hele tijd je best doen om aardig gevonden te worden of succesvol te zijn, om dat kwetsbare zelfbeeld te beschermen.

Het onderscheid tussen 'echte' en defensieve zelfwaardering reikt verder dan alleen het zelfbeeld; het heeft ook implicaties voor andere variabelen die gerelateerd zijn aan werk en prestatie, te weten, authenticiteit, motivatie en inspiratie. 


\section{Authenticiteit}

Authenticiteit is 'in'. Na de economische groei en de hectische jacht op carrière en geld in de jaren negentig, hebben we nu behoefte aan dingen die 'echt' zijn - of dat nu gaat om voedsel (authentieke koekjes volgens grootmoeders recept), meubilair (authentiek oud hout) of mensen. In ons empirisch onderzoek (Vonk e.a., 2004, op basis van een vragenlijst van Goldman \& Kernis, 2002) konden we twee aspecten van authenticiteit onderscheiden, namelijk 'naar binnen' gericht (in contact staan met je eigen gevoelens en drijfveren) en 'naar buiten' (congruentie tussen enerzijds het innerlijk en anderzijds het gedrag en relaties met anderen).

Mensen kunnen niet authentiek zijn wanneer ze de bron van hun zelfwaardering buiten zichzelf zoeken (in succes en bevestiging door anderen). Door de aandacht naar buiten te richten, raken ze (a) het contact kwijt met de waarden die ze intrinsiek belangrijk vinden en (b) is hun gedrag ook niet meer in overeenstemming daarmee. Er is dus een sterke relatie tussen authenticiteit en 'echte' zelfwaardering (zie ook Kernis \& Goldman, 2002).

\section{Motivatie}

Mensen met een hoge defensieve zelfwaardering moeten eigenlijk altijd voeding geven aan hun 'ego'. Dit betekent dat hun werk ego-georiënteerd is: men werkt ergens aan om (anderen of zichzelf) te bewijzen dat men het kan, dus om het zelfbeeld op te peppen wanneer het lukt, of te vermijden dat het een deuk oploopt in geval van mislukking. Het gevolg hiervan is dat de intrinsieke motivatie wordt ondermijnd (Ryan, 1982; Rawsthorne \& Elliot, 1999; vgl. Van Yperen, 2003). De tegenhanger van ego-oriëntatie is taak-oriëntatie; in de meer populaire literatuur bekend als 'flow' (Csikszentmihaly, 1992). Bij taak-oriëntatie gaat men geheel op in de taak, zonder aan iets anders te denken. Dit is geassocieerd met betere prestaties, meer creativiteit en sterkere gevoelens van welbevinden.

In de race naar meer geld en succes, die eind vorige eeuw gaande is geweest voor veel mensen, is dit onderscheid van belang. Ik vermoed dat het streven naar hogere bonussen, een hogere positie, een nog groter bedrijf (fusies) en andere indicatoren van succes voor een belangrijk deel wordt ingegeven door ego-gerelateerde motieven. Het zijn allemaal bronnen van bevestiging. Zolang de jacht hierop gaande is, staan mensen niet in contact met wat ze echt willen. Sheldon en Elliot (1999) spreken in dit geval van een lage 'self-concordance': de dagelijkse strevingen zijn niet in overeenstemming met de werkelijke intrinsieke doelen. Dit heeft niet alleen gevolgen voor de integriteit (denk aan het zich toe-eigenen van te hoge bonussen, in het streven om nog meer geld te verdienen of niet onder te doen voor een ander, d.i. niet minder waard te willen zijn); het gaat ook op een of andere manier 'knagen', men voelt zich onvoldaan en denkt dat een hogere beloning (of hogere status, etc.) de oplossing is. Dat is echter niet het geval, want het bereiken van niet-intrinsieke aspiraties verhoogt nauwelijks het welzijn (Kasser \& Ryan, 1993, 1996, 2001). In al dit soort gevallen zal het bereiken van de gestelde doelen nooit echt voldoening geven, simpelweg doordat men in het verkeerde water zit te vissen.

We zouden dan ook kunnen stellen dat de huidige economische terugval psychologisch gezien een voordeel heeft: Het dwingt mensen in zekere zin om 'pas op de plaats' te maken en de aandacht weer naar binnen te richten.

\section{Inspiratie}


Naast authenticiteit is er nog een andere 'hit' onder managers: geïnspireerd leiderschap. Uit het voorafgaande volgt dat pogingen om inspirerend te zijn met de bedoeling daarmee succesvoller te worden of meer waardering te oogsten, gedoemd zijn te mislukken. Inspiratie ontstaat in mijn opvatting alleen bij intrinsieke motivatie en bij een taak-georiënteerde houding. Het nastreven van inspiratie als doel is dus zinloos. Inspiratie ontstaat vanzelf wanneer men in contact staat met de eigen innerlijke drijfveren en werk doet dat daarbij past. Voor veel leidinggevenden is het dan ook belangrijker zichzelf díe vraag te stellen: Voor de meeste mensen geldt dat, naarmate ze hoger klimmen op de carrièreladder, ze steeds minder het werk doen waar ze ooit mee begonnen zijn; het werk waardoor ze zich ooit geïnspireerd en gedreven voelden. Dit betekent dat men het contact verliest met de oorspronkelijke drijfveren, met de drang om bepaalde dingen op te bouwen en om het beste van zichzelf tot uiting te brengen in het werk - een drang die er ooit toe leidde dat men dit werk ging doen en er goed in was. Wanneer het contact met de innerlijke drijfveren weer wordt hersteld, komt de inspiratie vanzelf. Dit kan vervolgens ook weer het welzijn en de prestaties van de ondergeschikten bevorderen: intrinsiek gemotiveerde leidinggevenden kunnen op hun beurt weer de intrinsieke motivatie van hun werknemers versterken, doordat ze als rolmodel fungeren en eerder een omgeving creëren waarin autonomie van werknemers wordt ondersteund (Deci \& Ryan, 2002).

\section{Waarheid en positieve psychologie}

Het voorafgaande suggereert dat het antwoord op veel problemen simpel is: Zorg dat je in contact komt met jezelf, dat je gedrag en je keuzes corresponderen met je innerlijke waarden en doelen, en de rest ('echte' zelfwaardering, inspiratie, enzovoort) komt vanzelf. Dat klinkt te mooi om waar te zijn. En dat is het ook.

Hoewel de self-determination theorie een uitermate vruchtbare en inspirerende basis is bij training en coaching, gaat zij voorbij aan enkele harde gegevenheden. Een daarvan is dat mensen van nature sociale dieren zijn die zich iets aantrekken van anderen. Dat is ook nodig bij het handhaven van bijvoorbeeld groepsnormen en een soepel sociaal verkeer. Laten we ons heel even iemand voorstellen die geen goede prestaties levert, door anderen niet aardig wordt gevonden, niets bijdraagt aan de groep of de samenleving, en toch een solide zelfwaardering weet te handhaven onder het motto "Ik ben trouw aan mezelf". Door deze voorstelling wordt duidelijk dat het eerder onaangepast is om niet gevoelig te zijn voor de signalen van anderen (cf. Leary, 1999, 2002). Mensen leven en werken met elkaar in sociale systemen, en die systemen functioneren voor een belangrijk deel juist doordat mensen gevoelig zijn voor wat anderen van hen vinden en zich aanpassen wanneer ze signalen krijgen dat ze iets verkeerd doen. We zouden zelfs de stelling kunnen verdedigen dat een autonome zelfwaardering, die niet door anderen wordt beïnvloed, de ultieme vorm van zelfverdediging en een totalitair ego weerspiegelt, omdat het kan wijzen op rigiditeit, gebrek aan openheid en geen bereidheid zichzelf te ontwikkelen.

Ook resultaten van empirisch onderzoek laten zien dat de zelfwaardering van mensen sterk kan dalen of stijgen met de reacties die ze van anderen krijgen (Leary e.a., 2003, Vonk e.a., 2004). Bovendien blijkt dat positieve feedback van buitenaf gedurende langere tijd niet alleen de zelfwaardering verhoogt, maar ook de intrinsieke motivatie, het belang dat wordt toegekend aan intrinsieke waarden (bijv. vriendschap, een betere wereld, zelfontwikkeling, in plaats van bijv. materiële welvaart, erkenning, status) en de tevredenheid over het dagelijks 
werk (Vonk, 2003). Evidentie voor de positieve effecten van 'self-determination' komt voornamelijk uit correlationeel onderzoek; ons eigen experimenteel onderzoek suggereert dat de weg naar authenticiteit, inspiratie en al die mooie dingen eerder loopt via bevredigende contacten met anderen waarin men zichzelf door anderen gezien en gewaardeerd voelt (Vonk, Jolij, Stoeller \& Boog, 2004).

Dit betekent niet dat de door de self-determination theorie beschreven positieve effecten niet mogelijk zijn. Het betekent wel dat, naast zelf-contact en autonomie (de twee peilers van zelfbepaling), ook een open houding naar de buitenwereld nodig is, die recht doet aan een werkelijkheid waarin mensen door anderen worden geraakt en soms uit balans gebracht.

De geringe aandacht voor dit aspect hangt naar mijn idee samen met een fundamenteel probleem in de positieve psychologie - waar de self-determination theorie een onderdeel van is -, die momenteel in opkomst is. Deze stroming heeft haar oorsprong in de humanistische jaren zestig-psychologie en legt het accent op "het positieve in de mens". Impliciet wordt daarbij uitgegaan van de Amerikaanse droom dat iedereen kan worden wat hij of zij echt wil. Daarmee gaat deze benadering voorbij aan een belangrijk gegeven van ieders leven - in goed Amerikaans: shit happens. Afwijzing en mislukking hoort erbij, en wanneer het je vaak genoeg overkomt wordt je zelfwaardering aangetast. Dat geldt ook voor diegenen die menen dat hun zelfwaardering niet door anderen wordt beïnvloed (Leary e.a., 2003).

Ik ben ervan overtuigd dat het voor mensen volkomen natuurlijk is om (a) gevoelig te zijn voor reacties van anderen en voor alle sociale signalen die aangeven wat men waard is, en (b) zich tegen negatieve signalen teweer te stellen met behulp van oogkleppen, een roze bril en wat er ook nodig is om een goed gevoel over zichzelf te handhaven.

Tegelijkertijd denk ik ook dat het mogelijk is deze natuurlijke neigingen te overwinnen. Mensen hebben, meer dan welk ander dier ook, het vermogen zelf keuzes te maken. Een van die keuzes is die tussen waarheid en troost. 'Troost' betekent: vasthouden aan zelfwaardering, aan de overtuiging dat alles goed geregeld is in de wereld, dat narigheid alleen diegenen overkomt die het verdienen, en in het algemeen aan alles wat nodig is om te zorgen dat we ons goed voelen. 'Waarheid' betekent: accepteren dat we soms fouten maken, dat sommige mensen ons aardig vinden en ons waarderen en andere niet, dat dingen kunnen mislukken door puur toeval of door onze eigen stommiteit, dat we net als ieder ander zijn, dat we soms tevreden zijn met onszelf en soms niet, dat we leven in een wereld waarin veel schoonheid maar ook veel lelijkheid aanwezig is, waarin we niet alles naar onze hand kunnen zetten, en dat we net als ieder ander uiteindelijk sterfelijk zijn. Waarheid betekent dat we de dingen zien zoals ze zijn, waardoor een bron van wrijving (het spanningsveld tussen realiteit en het hedonistische streven naar positieve gevoelens) wordt opgeheven, maar het betekent ook dat pijnlijke feiten worden toegelaten.

In de psychologie van het afgelopen decennium ligt een sterk accent op processen die voor mensen oncontroleerbaar en instinctief zijn. In de evolutionaire en sociobiologische benadering wordt de mens gezien als het product van genetische eigenschappen die in de loop van de evolutie adaptief zijn geweest, en die nog altijd ons gedrag in hoge mate sturen, bijvoorbeeld als het gaat om partnerkeuze en de behoefte aan affiliatie (Buss, 1999; Buunk \& Dijkstra, 2004) of om prosociaal en antisociaal gedrag (bijv. Geen, 1998; Modde, 2004). In een heel andere hoek, de sociale cognitie, wordt steeds meer aandacht besteed aan automatische, oncontroleerbare processen die het denken, doen en voelen van mensen sturen (bijv. Bargh \& Chartrand, 1999; Dijksterhuis, 1998; Wegner \& Bargh, 1998). Hoewel deze 
beide onderzoekstradities sterk van elkaar verschillen, hebben ze met elkaar gemeen dat de mens wordt gezien als iemand die weinig controle heeft over zijn eigen keuzes en wordt gestuurd door onbewuste drijfveren.

Dat dit inderdaad vaak zo is blijkt uit talloze onderzoeksresultaten. Dat betekent echter niet dat het onmogelijk is voor mensen om in vrijheid keuzes te maken. Naast een automatische piloot die ons leven makkelijker maakt, en naast de instinctieve drijfveren die we gemeen hebben met andere dieren, hebben we als mensen ook hogere cognitieve vermogens die ons in staat stellen verschillende belangen af te wegen, niet alleen de korte maar ook de langere termijn in beschouwing te nemen, en onszelf af en toe te herinneren aan wat nu echt van waarde is in ons leven. Het is dit vermogen dat we nodig hebben om de dingen te zien zoals ze werkelijk zijn en tegelijkertijd contact te houden met wat waardevol voor ons is.

Om aan dit aspect van het menselijk functioneren meer aandacht te geven, is wellicht een combinatie nodig van de cynische sociale psychologie, die de gebreken van mensen beschrijft, en de optimistische positieve psychologie: we moeten niet alleen erkennen dat allerhande onhebbelijke verdedingsmechanismen volkomen natuurlijke en automatische aspecten vormen van het menselijk functioneren, juist in situaties waar het ego wordt bedreigd; maar ook dat mensen meer zijn dan het product van instincten en automatismen, en het vermogen hebben hun natuurlijke neigingen te overwinnen en daarmee keuzevrijheid te creëren. Dit opent de weg naar meer realistische vormen van persoonlijke autonomie en naar een onderzoeksagenda voor sociaal psychologen die ontsnapt aan het dilemma tussen romantiek en cynisme.

Literatuur

\section{Literatuur}

- Aberson, C. L., Healy, M. \& Romero, V. (2000). Ingroup bias and self-esteem: A meta-analysis. Personality and Social Psychology Review, 4(2), 157-173.

- Alloy, L. B. \& Abramson, L. Y. (1979). Judgment of contingency in depressed and nondepressed students: Sadder but wiser? Journal of Experimental Psychology: General, 108(4), 441-485.

- Armor, D.A. (1999). The illusion of objectivity: A bias in the perception of freedom from bias., U California, Los Angeles, US, 1.

- Bargh, J.A., \& Chartrand, T. L. (1999). The unbearable automaticity of being. American Psychologist, 54, 462-479.

- Wegner, D. M., \& Bargh, J. A. (1998). Control and automaticity in social life. In D. Gilbert, S. Fiske, \& G. Lindzey (Eds.), Handbook of social psychology (4/e). Boston: McGraw- Hill.

- Baumeister, R.F. (1998). The self. In D.Gilbert, S.T.Fiske, \& G.Lindzey (Eds.), Handbook of social psychology (4th ed., Vol.1, pp.680-740). New York: McGrawHill.

- Baumeister, R.F., Campbell, J.D. Krueger, J.I. \& Vohs, K.D. (2003). Does high selfesteem cause better performance, interpersonal success, happiness, or healthier lifestyles? Psychological Science in the Public Interest, 4, 1-44.

- Baumeister, R. F., Heatherton, T. F. \& Tice, D. M. (1993). When ego threats lead to self-regulation failure: Negative consequences of high self-esteem. Journal of Personality and Social Psychology, 64, 141-156. 
- Baumeister, R. F., Smart, L. \& Boden, J. M. (1996). Relation of threatened egotism to violence and aggression: The dark side of high self-esteem. Psychological Review, 103(1), 5-33.

- Baumeister, R. F. \& Tice, D. M. (1985). Self-esteem and responses to success and failure: Subsequent performance and intrinsic motivation. Journal of Personality, 53(3), 450-467.

- Blaine, B. \& Crocker, J. (1993). Self-esteem and self-serving biases in reactions to positive and negative events: An integrative review. In R. F. Baumeister (Ed.), Selfesteem: The puzzle of low self-regard (pp. 55-85). New York: Plenum Press.

- Buss, D.M. (1999). Evolutionary psychology: The new science of the mind. Boston: Allyn and Bacon.

- Buunk, B. \& Dijkstra, P. (2004). Attractie en relaties. In R. Vonk (Red.), Sociale psychologie. Groningen: Wolters-Noordhof.

- Colvin, C. R. \& Block, J. (1994). Do positive illusions foster mental health? An examination of the Taylor and Brown formulation. Psychological Bulletin, 116(1), 320.

- Crocker, J., \& Park, L. E. (2003). Seeking self-esteem: Construction, maintenance, and protection of self-worth. In M. Leary \& J. Tangney (Eds.), Handbook of self and identity (pp. 291-313). New York: Guilford.

- Cross, P. (1977). Not can but will college teaching be improved. New Directions for Higher Education, 17, 1-15.

- Damon, W. (1995a). 'I'm terrific'- and demoralized. Education Week, 33.

- Dawes, R. M. (1994). House of cards: Psychology and Psychotherapy built on myth. New York: Free Press.

- Deci, E. L., \& Ryan, R. M. (1995). Human autonomy: The basis for true self-esteem. In M. Kernis (Ed.), Efficacy, agency and self-esteem (pp. 31-49). New York: Plenum.

- Deci, E. L., \& Ryan, R. M. (Eds.). (2002a). Handbook of self-determination research. Rochester, NY: University of Rochester Press.

- Diener, E., Wolsic, B., \& Fujita, F. (1995). Physical attractiveness and subjective wellbeing. Journal of Personality and Social Psychology, 69(1), 120-129.

- Dijksterhuis, A. (1998). Automaticiteit en controle. In R. Vonk (Red.), Cognitieve sociale psychologie, p. 287-320. Utrecht: Lemma.

- Ehrlinger, J., \& Dunning, D. (2003). How chronic self-views influence (and potentially mislead) estimates of performance. Journal of Personality and Social Psychology, 84(1), 5-17.

- Gabriel, M. T., Critelli, J. W., \& Ee, J. S. (1994). Narcissistic illusions in selfevaluations of intelligence and attractiveness. Journal of Personality, 62(1), 143-155.

- Geen, R.G. (1998). Aggression and antisocial behavior. In D.T. Gilbert, S.T. Fiske, \& G. Lindzey (Eds.), The handbook of social psychology. New York: McGraw Hill.

- Goldman, B. \& Kernis, M. (2002). Authenticity: A multicomponent model. Ter publicatie aangeboden manuscript.

- Gilovich, T. (1991). How we know what isn't so: The fallibility of human reason in everyday life. New York: Free Press.

- Gilovich, T., Kruger, J., \& Savitsky, K. (1999). Everyday egocentrism and everyday interpersonal problems. In R. Kowalski \& M. Leary (Eds.), The social psychology of emotional and behavioral problems: Interfaces of social and clinical psychology (pp. 69-95). Washington, DC: American Psychological Association.

- Greenberg, J., Solomon, S. \& Pyszczynski, T. (1997). Terror management theory of self-esteem and cultural worldviews: Empirical assessments and conceptual 
refinements. In M.Zanna (Ed.), Advances in experimental social psychology (Vol.29, pp.61-139). London: Academic.

- Greenwald, A. G. (1980). The totalitarian ego: Fabrication and revision of personal history. American Psychologist, 35(7), 603-618.

- Harter, S. (1993). Causes and consequences of low self esteem in children and adolescents. In R. F. Baumeister (Ed.), Self-esteem: The puzzle of low self regard. New York: Plenum.

- Heatherton, T. F., \& Vohs, K. D. (2000). Interpersonal evaluations following threats to self: Role of self-esteem. Journal of Personality and Social Psychology, 78, 725-736.

- Hewitt, J. P. (1998). The Myth of Self-Esteem: Finding Happiness and Solving Problems in America. New York: St. Martin's Press.

- Jansen, D. \& Vonk, R. (2004). Contingente zelfwaardering: relaties met boosheid/vijandigheid, narcisme, stabiliteit en niveau van zelfwaardering. Ter publicatie aangeboden manuscript.

- Jones, E.E. (1964). Ingratiation. New York: Appleton-Century-Crofts.

- Joiner, T. E., Jr., Vohs, K. D., Katz, J., Kwon, P., \& Kline, J. P. (2003). Excessive self-enchancement and interpersonal functioning in roommate relationships: Her virtue is his vice? Self and Identity, 2(1), 21-30.

- Kasser, T., \& Ryan, R. M. (1993). A dark side of the American dream: Correlates of financial succes as a central life aspiration. Journal of Personality and Social Psychology, 65, 410-422.

- Kasser, T., \& Ryan, R. M. (1996). Further examining the American dream: Differential correlates of intrinsic and extrinsic goals. Personality and Social Psychology Bulletin, 22, 280-287.

- Kernis, M. H. (2003). Toward a conceptualization of optimal self-esteem. Psychological Inquiry, 14.

- Kipnis, D. (1976). The powerholders. Chicago: The University of Chicago Press.

- Koole, S. (2004). Het zelfbeeld. In R. Vonk (Red.), Sociale psychologie. Groningen: Wolters-Noordhof.

- Leary, M. R. (1999). The social and psychological importance of self-esteem. In R. M. Kowalski \& M. R. Leary (Eds.), The social psychology of emotional and behavioral problems. Washington, D.C.: American Psychological Association.

- Leary, M. R. (2002). The self as a source of relational difficulties. Self and Identity, $1(2), 137-142$.

- Leary, M. R., \& Baumeister, R. F. (2000). The nature and function of self-esteem: sociometer theory. Advances in experimental social psychology, 32, 1-62.

- Leary, M. R., Gallagher, B., Fors, E., Buttermore, N., Baldwin, E., Kennedy, K., \& Mills, A. (2003). The invalidity of disclaimers about the effects of social feedback on self-esteem. Personality and Social Psychology Bulletin, 29, 623-636.

- Leary, M. R., \& Kowalski, R. M. (1995). Social anxiety. New York: Guilford.

- London, T. (1997). The case against self-esteem: Alternative philosophies toward self that would raise the probability of pleasurable and productive living. Journal of Rational Emotive and Cognitive-Behavior Therapy, 15, 19-29.

- Lyubomirsky, S. (2001). Why are some people happier than others? The role of cognitive and motivational processes in well-being. American Psychologist, 56(3), 239-249.

- Modde, J.J. (2004). Prosociaal en antisociaal gedrag. In R. Vonk (Red.), Sociale psychologie. Groningen: Wolters-Noordhof. 
- Murray, S. L., Holmes, J. G., Griffin, D. W., Bellavia, G., \& Rose, P. (2001). The mismeasure of love: How self-doubt contaminates relationship beliefs. Personality and Social Psychology Bulletin, 27(4), 423-436.

- Pronin, E., Lin, D.Y. \& Ross, L. (2002). The bias blind spot: Perceptions of bias in self versus others. Personality and Social Psychology Bulletin, 28(3), 369-381.

- Rawsthorne, L. J., \& Elliot, A. J. (1999). Achievement goals and intrinsic motivation: a meta-analytic review. Personality and Social Psychology Review, 3, 326-344.

- Ryan, M. R. (1982). Control and information in the intrapersonal sphere: an extension of cognitive evaluation theory. Journal of Personality and Social Psychology, 43, 450461.

- Sedikides, C. (1993). Assessment, enhancement, and verification determinants of the self-evaluation process. Journal of Personality and Social Psychology, 65(2), 317-338.

- Sheldon, K. M., \& Elliot, A. J. (1999). Goal striving, need satisfaction, and longitudinal well-being: The self-concordance model. Journal of Personality and Social Psychology, 76(3), 482-497.

- Shrauger, J. S., \& Schoeneman, T. J. (1979). Symbolic interactionist view of selfconcept: Through the looking glass darkly. Psychological Bulletin, 86(3), 549-573.

- Steele, C. M. (1988). The psychology of self-affirmation: Sustaining the integrity of the self. Advances in Experimental Social Psychology, 31, 261-302.

- Svenson, O. (1981). Are we all less risky and more skillful than our fellow drivers? Acta Psychologica, 47(2), 143-148.

- Taylor, J. (1989). The effects of personal and competitive self-efficacy and differential outcome feedback on subsequent self-efficacy and performance. Cognitive Therapy and Research, 13(1), 67-79.

- Taylor, S. E., \& Brown, J. D. (1988). Illusion and well-being: A social psychological perspective on mental health. Psychological Bulletin, 103(2), 193-210.

- Taylor, S. E., Lerner, J. S., Sherman, D. K., Sage, R. M., \& McDowell, N. K. (2003). Portrait of the Self-Enhancer: Well Adjusted and Well Liked or Maladjusted and Friendless? Journal of Personality and Social Psychology, 84, 165-176.

- Van Yperen, N.W. (2003). Task interest and actual performance: The moderating effects of assigned and adopted purpose goals. Journal of Personality and Social Psychology, 85, 1006-1015.

- Vohs, K. D., \& Heatherton, T. F. (2001). Self-esteem and threats to self: Implications for self-construals and interpersonal perceptions. Journal of Personality and Social Psychology, 81, 1103-1118.

- Vonk, R. (1998). The slime effect: Suspicion and dislike of likeable behavior toward superiors. Journal of Personality and Social Psychology, 74(4), 849-864.

- Vonk, R. (2001). Aversive self-presentations. In R.M.Kowalski (Ed.), Behaving badly: Aversive behaviors in interpersonal relationships (pp.79-115). Washington, DC, US: American Psychological Association.

- Vonk, R. (2002). De waarnemer waargenomen. De Psycholoog, 37, 574-580.

- Vonk, R. (2003). Zelfwaardering bestaat niet. Plenaire lezing bij het ASPO-congres, Maastricht, december 2003.

- Vonk, R., Jolij, J., Stoeller, T., \& Boog, I. (2004). Self-esteem, happiness, and motivation: Effects of unconditional positive regard and self-reflection. In voorbereiding.

- Wilson, T. D. (2002). Strangers to ourselves: Discovering the adaptive unconscious. Cambridge, MA, US: Belknap Press/Harvard University Press. 